Barry Gerhart*

\title{
Human Resources and Business Performance: Findings, Unanswered Questions, and an Alternative Approach $^{* *}$
}

In 1996, Becker and Gerhart noted that much of the work on human resources (HR) and performance had traditionally been conducted at the individual level of analysis. However, in the 1990s, empirical research on HR and performance increasingly moved to the plant/unit and firm level of analysis with a new emphasis on understanding how HR practices influence business performance at these higher levels. In the present article, I describe the empirical findings of this evolving literature, unanswered questions, and an approach to the issue that differs from what has come to be the typical approach over the past 10 years or so.

Key words: Human Resources, Performance, Employee Relations, Employee Attitudes, Methodology

* Barry Gerhart, Professor of Management \& Human Resources, Bruce R. Ellig Distinguished Chair in Pay and Organizational Effectiveness, School of Business, University of Wisconsin-Madison, 975 University Avenue, Madison, WI 53706-1323, USA, Phone: ++1 608262 3895, Fax: ++1 608265 5372, e-mail: bgergart@bus.wisc.edu.

** Article received: February 27, 2004

Revised version accepted after double blind review: February 22, 2005. 


\section{Findings on HR and Business Performance}

Early efforts to link HR practices to business performance generally focused on a single practice or area of HR. For example, business performance was found to be stronger where the industrial relations climate was more favorable (e.g., lower levels of grievances and conflict, better employee attitudes) and where the use of labor-management cooperation programs was greater (Cutcher-Gershenfeld 1991; Katz/Kochan/Gobeille 1983; Katz/Kochan/Weber 1985). This work was conducted at the plant/unit level of analysis (and typically in unionized settings). Other work, at the firm level of analysis, reported that business performance was stronger in firms emphasizing pay for performance in managerial compensation (Gerhart/Milkovich 1990) and in firms using more valid employee selection procedures (Terpstra/Rozell 1993).

Subsequent research expanded the conception and measurement of HR to include an array of practices. To some extent, "AMO theory" (Boxall/Purcell 2003) has evolved as a model to help guide choice of HR practices to study. AMO refers to ability-motivation opportunity (Appelbaum et al. 2000; Bailey 1993; Gerhart, forthcoming; Huselid 1995; Ichniowski et al. 1996). Under the AMO model, HR practices are expected to influence business performance via the workforce's ability (e.g., using selective hiring, training), motivation (e.g., using pay for performance), and opportunity to contribute (e.g., using teams, suggestion systems).

At the plant/facility level, key studies showing links between HR practices and performance were conducted by Arthur (1994), MacDuffie (1995), and Ichniowski/ Shaw/Prennushi (1997) in manufacturing and in the service sector by Batt (2002). At the firm level, an early and influential study was conducted by Huselid (1995), followed by Delery and Doty (1996). For reviews of these and related studies, see Becker and Gerhart (1996), Boxall and Purcell (2003), and Gerhart (1999, forthcoming).

The empirical work generally reports the same finding: the choice of HR practices is related to business performance, often strongly. (See Cappelli and Neumark for an empirical exception and Godard 2004 for a less optimistic review.) For example, Gerhart's (1999) review found that a one standard deviation increase in HR system practices (relative to the mean) designed to enhance workforce ability, motivation, and opportunity to contribute was associated with roughly 20 percent better firm financial performance. Consider that this finding means that firms one standard deviation above the mean are at $120 \%$ of mean performance, while those one standard deviation below the mean are at 80 percent of mean performance, making for a $120 / 80=$ 50 percent advantage of being +1 standard deviation versus -1 standard deviation. This is a large difference.

How have such studies been received by HR scholars? An examination of the HR Division, Academy of Management, Scholarly Achievement Award (best article of the year) winning studies reveals that since 1990, the majority of award-winning articles have used either plant or firm performance as a major dependent variable (http://www.hrdiv.org/) and one or more HR practices as the independent variable(s). In all such studies, HR and performance were positively related. The finding that "HR matters" seems to be well-received by those studying HR and the ability to cite hard, quantitative evidence in support of the importance of the field is also no doubt welcome. 
Also notable is how robust the findings from research on HR and performance have been (Guest et al. 2003, 294):

"a large majority of published studies find an association between HR practices and firm performance, regardless of whether they are cross-sectional or longitudinal, whether conducted at establishment or company level, whether based on strong performance data or subjective estimates, whatever sector they are based on, whatever operational definition of HR is used and wherever they are conducted."

\section{Unanswered Questions}

Nevertheless, Guest et al. $(2003,295)$ also note that there are concerns with this line of research:

"Despite the positive thrust of most published empirical findings, Wood (1999) among others has noted that the quality of the research base supporting the relationship between HR and performance is relatively weak....questions remain about the measurement of both HR and performance, and about the weight and relevance of tests of association and causation."

I agree that "questions remain." These are as follows. First, the effect sizes described above, which are quite large, are actually uncorrected for (random) measurement error (Gerhart 1999; Gerhart et al. 2000). Upon correcting the effect sizes, they become even larger. Consider that to correct an unstandardized regression coefficient for random measurement error, one divides it by its reliability (Gerhart 1999). ${ }^{1}$ Consider also that although the main source of random error in firm-level HR measures is due to the sampling of raters, almost without exception, studies of HR-performance ignore interrater reliability. Instead, they regularly report only coefficient alpha (typically in the .70 range), an index of reliability that addresses (only) internal consistency of items (in its typical application).

However, based on Gerhart et al. (2000), as well as the subsequent Wright et al. (2001) study and its three additional samples, the interrater reliability of HR measures used in firm level studies is probably no better than .20 to .30. (This is consistent with the literature in applied psychology on the reliability of single-rater measures, Gerhart 1999.) A complete estimate of reliability would combine both the coefficient alpha (take .70 as the estimate) and interrater reliability estimates (take .30 as the estimate), which would yield a total reliability of roughly $.20 .^{2}$ Taking the uncorrected effect size of $20 \%$ noted earlier, the corrected effect size then would be $20 \% / .20=100 \%$.

1 By contrast, the correction for attenuation (of a bivariate correlation coefficient) is accomplished by dividing by the product of the square root of each variable's reliability.

2 Random measurement error can come from multiple sources (e.g., sampling of items, sampling of raters). In this situation, using a single reliability coefficient (coefficient alpha reliability or inter-rater reliability) yields an over-estimate of total measurement reliability (Schmidt/Hunter 1996). The best approach in the (typical) case of multiple sources of measurement error is to use generalizability theory (Gerhart et al. 2000). However, a rough rule of thumb is that total reliability can be approximated by the product of the single-source reliability coefficients (DeShon 1998). For example, with a coefficient alpha of .70 and an interrater reliability of .30 (toward the high end of the range based on Gerhart et al. and Wright et al. 2001), the total reliability would be $.70 \times .30=.21$, or roughly .20. 
This effect size is so large as to perhaps not be credible. Indeed, in their review, Becker and Huselid $(1998,69)$ described an effect size of $90 \%$ as "implausibly large". If they are correct, then this is all the more reason to revisit the methodology of the studies on which such an effect size is based. At this point, the explanation for such a large "corrected" effect size, especially in firm level of analysis studies, is not clear. (Note that Gerhart/Wright/McMahan 2000 find higher reliabilities at the plant level of analysis and thus correcting for measurement error likely has less impact in such studies.)

Gerhart (1999) suggests the possibility of reverse causation such that high performing firms report higher levels of what are believed to be best-practice HR activities (i.e., HR reports are endogenous to firm performance). Huselid and Becker (2000) are not persuaded by this argument nor do they accept Gerhart et al.'s reliability estimates. This, in turn, means they do not accept the corrected effect sizes implied by such reliabilities. (See however, the reply of Gerhart/Wright/McMahan 2000.) If Huselid and Becker were to choose a source of potential bias, it would be omitted variable bias. In their view, high performing firms not only have effective HR practices, but also effective practices in other areas (finance, operations, marketing, etc.). If these effective practices are not included in the firm performance equation and if they correlate with HR practices (net of any control variables), then the coefficient on HR may be biased upward by picking up some of their omitted positive effects on firm performance.

A second and related unanswered question has to do with causality. Although there is evidence to suggest that HR is related to business performance, there is almost no evidence to document that that the causal relationship is of the form HR $\rightarrow$ business performance rather than some other causal form. In 1996, Becker and Gerhart stated that "Future work...must elaborate on the black box between a firm's HR system and the firm's bottom line" (793). This has not happened. Without evidence on intervening/mediating variables, the specific causal model remains unclear.

A related issue is the need to include data from different sources and levels of analysis (Bowen/Ostroff 2004), given that HR system policies (often measured by asking HR executives) are typically theorized to operate through individual level employee reactions such as motivation, ability, and opportunity (Bailey 1993; Boxall/Purcell 2003; Ichniowski et al. 1996). Yet, this multi-level/multi-source data (and thus corresponding tests of intervening processes) is largely absent from the HR systems literature (Becker/Gerhart 1996; Gerhart, forthcoming).

In such a situation, one should perhaps be hesitant to make strong policy recommendations. One test is whether, if you owned your own firm or were a manager making this decision, would you would invest the resources to implement the HR practices that have been included in the above studies, if such practices are not already in place? Based on evidence that the implementation of HR "best" practices, especially multiple practices (Osterman 2000), continues to be limited, despite the very large and positive effect sizes reported, it appears that the answer is "no" in many organizations.

Third, although there seems to be a widespread belief that the HR-business performance relationship depends on contextual factors (e.g., business strategy, national 
culture, laws and institutions), there is surprisingly little empirical evidence to date to support this belief (Dyer/Reeves 1994; Gerhart et al. 1996; Gerhart, forthcoming; Godard 2004; Wright/Sherman 1999). This is a concern because it seems unlikely that one set of HR practices will work equally well no matter what the context (e.g., business strategy, employee attributes, institutional setting). If studies of the HRperformance relationship continue to find no evidence that context matters, either the contingency theory central to strategic HR is flawed or the methodology, part of which is the measurement of HR, is flawed.

Fourth, financial performance is typically used as the dependent variable in this line of research. Some observers (e.g., Godard 2004; Godard/Delaney 2000) argue that this is too narrow of a focus. A broader definition of effectiveness would expand the set of relevant stakeholders to, at a minimum, include employees. That a set of HR practices may contribute to business performance does not necessarily provide a clear picture of their effects on worker welfare. It seems important to design research that accounts for how employees view their employment situation. Of course, not every individual study needs to address all relevant dependent variables, but at the level of the field of study, it would be useful to see more attention to worker outcomes.

Fifth, and a major focus, what exactly is "HR" and how should it be measured and studied? One of the earliest concerns with the Huselid (1995) study was with the items used to measure HR. Huselid used two HR scales, "employee skills and organizational structures" and "employee motivation." Consider that his factor analysis showed that the two highest loading items on the first scale were "What is the proportion of the workforce whose job has been subjected to formal job analysis?" and "What is the proportion of the workforce who are included in formal information sharing program (e.g., a newsletter)?"

Do such these items capture what is most fundamental about HR as a source of competitive advantage? To create sustained competitive advantage, the resource-based view (RBV) of the firm (e.g., Barney 1991) posits that a resource must not only create value, but do so in a way that is rare and difficult for competitors to imitate (or to substitute for). Items of the sort described just above may not meet these tests. Even the most basic test, that the resource create value, is open to question with items that ask the degree to which jobs have been subjected to job analysis and the degree to which employees receive a newsletter.

Other items on Huselid's (1995) "employee skills and organizational structures" scale and on his other HR practices scale, "employee motivation," (e.g., hours of training, use of employee testing, selectivity in hiring, performance-based compensation) have more face validity as practices that can create value. By the logic of the HR practices and business performance paradigm, firms would want to evaluate whether they are making sufficient use of such HR practices. If not, greater emphasis on these practices might provide a path toward better performance.

However, as noted earlier, there are important unanswered questions and issues regarding this standard HR practices and business performance paradigm. These concern the credibility of (very large) effect sizes, the lack of evidence regarding causality, the failure to support predictions of fit, and too narrow of a definition of effectiveness. 
These concerns suggest the need to reconsider (or at least supplement) the standard paradigm that has been used in the literature to study HR and business performance. A fundamental part of this standard paradigm is the definition and measurement of HR in terms of practices and (typically) in terms of what proportion of employees are covered by such practices. Perhaps an alternative approach would be useful, either to replace the current paradigm or as a means of making it stronger and more valid.

\section{An Alternative Approach}

The concerns noted above have led us and others to consider alternative ways to define HR and to study its effect on firm performance. Our approach is to focus on employee relations, especially as seen from the point of view of employees, which we feel is one of the ultimate goals of HR. Our view is that positive employee relations and attitudes can be achieved via multiple paths using alternative combinations of HR practices. The existence of such multiple paths may help explain the lack of empirical support for fit between simple, generic HR strategy typologies and simple, generic business strategy typologies. We also believe that this alternative approach will ultimately help sort out issues of causality, given that it incorporates what would be seen as an important intervening variable in the HR practices paradigm: employee relations and attitudes. We also believe that this focus on employee relations and attitudes effectively incorporates employees as a stakeholder in a way that a focus exclusively on HR practices cannot.

The resource-based-view (RBV) of the firm emphasizes how firms "look inside" for resources that not only add value, but are also rare and difficult to imitate and that can be leveraged to build sustained competitive advantage (Barney 1991). Industry characteristics and business strategy place limits on managerial discretion, but a significant amount remains. HR, and more specifically, employee relations, seems to fit well with the RBV. According to Pfeffer (1994), the success generated by human resource systems "is often not visible or transparent as to its source," which evokes Barney's (1991) concept of inimitability through causal ambiguity:

"it is often hard to comprehend the dynamics of a particular company and how it operates because the way people are managed often fits together in a system. It is easy to copy one thing but much more difficult to copy numerous things. This is because the change needs to be more comprehensive and also because the ability to understand the system of management practices is hindered by its very extensiveness."

Conceptual applications of the RBV approach to HR can be found in Lado and Wilson (1994), Barney and Wright (1998), and Gerhart, Trevor, and Graham (1996), but there is little in the way of empirical research. What is especially needed is evidence on what is arguably an especially valuable, yet difficult to imitate resource, which one finds by "looking inside" some organizations: employee relations. Imitating HR practices is one thing. Successfully imitating strong employee relations is quite another.

One research area of interest is that documenting a positive relationship between attitudes and performance at the individual level of analysis (see Judge et al. 2001 meta-analysis), between attitudes and financial performance at the facility level (Harter et al. 2002; Ryan/Schmit/Johnson 1996), and at the organization level, between attitudes and nonfinancial performance (Ostroff 1992). This line of research suggests that positive workforce attitude creates value. 
Only recently, however, has research documented a relationship between employee attitudes and financial performance at the firm level of analysis (Fulmer/ Gerhart/Scott 2003; Schneider et al. 2003). Fulmer et al. (2003, 966) explicitly incorporated the RBV framework in their study and focused on determining "whether superior firm-level employee relations effectively serve as an enduring resource that is associated with better financial and market performance relative to other firms".

To do so, they tracked companies on the Fortune list, "The 100 Best Companies to Work for in America" (Levering/Moskowitz 1998). Membership on the 100 Best list is determined primarily by an extensive employee attitude survey (mean of 136 employee respondents per firm). Interrater reliability of average employee attitude was .850. (This reliability far exceeds that of single-rater designs that have been typically used in the HR practices and performance literature.) In addition, the one-year testretest correlation of average employee attitude was .650 (and much higher, .940, when employee attitude was corrected for significant range restriction in attitudes of firms on this select list.)

Areas addressed by the attitude survey included credibility (e.g., "management keeps me informed about important issues," "integrity in carrying out vision with integrity"), respect (e.g., "caring for employees as individuals with personal lives," "management involves people in decisions that affect their jobs or work environment"), fairness (e.g., "impartiality - absence of favoritism in hiring and promotions", pride ("in work personal, job, individual contributions," “in work produced by one's team or group"), and camaraderie ("sense of "family' or "team"). Further information on the content of the employee survey can be found at www.greatplacetowork.com.

Employee relations/average employee attitudes of the high level observed for the 100 Best are arguably rare (only 100 make the list, of course), quite possibly difficult to imitate, and likely to create value in a whole host of ways (Fulmer et al. 2003). Strong employee relations allows for greater selectivity in hiring and retention, both of which raise average workforce quality. Strong employee relations is also likely to contribute to a more highly committed, engaged, and motivated workforce. When combined with an appropriately aligned set of roles that permit meaningful contributions by workers (e.g., increased responsibility and autonomy), the payoffs have the potential to be substantial.

Fulmer et al. (2003) compared the financial performance of the 100 Best companies over a several year period to two groups. The first group (value-weighted index) was designed to represent the broad market and included firms listed on the major U.S. stock exchanges (NYSE, AMEX, NASDAQ). The second group (matching firms) was composed of companies matched on the basis of industry, size, and operating performance.

Financial performance of the companies on the 100 Best List was generally superior to that of both comparison groups. Return on assets for the 100 Best companies during the three years following publication of the list was $9.03,9.15$, and $7.93 \%$, compared to $6.65,7.64$, and $6.96 \%$ for the matched firms. Total shareholder return for the three years following the publication of the 100 Best list was $82.2 \%$ versus $36.5 \%$ for the value-weighted index and $52.7 \%$ for the matched firms. 
In summary, Fulmer et al. (2003) found that that employee relations can provide substantial sustained competitive advantage (at least over the three year post-list period observed). Also worth emphasizing is what they did not find. It could be argued, for example, that strong employee relations can only be achieved by transferring wealth in some form (either as cash or in the form of benefits/programs employees value) from shareholders to employees. Fulmer et al. found no evidence of this sort of complete zero-sum model. Another possible finding would have been that employee relations and financial performance were unrelated. In our view, such a finding would also be of interest because it would indicate that financial performance is not necessarily compromised by strong employee relations.

The Fulmer et al. (2003) study is different from the standard HR practices and firm performance paradigm in that $\mathrm{HR}$ was defined in terms of employee relations as seen by employees, not in terms of proportion of employees covered by stated HR practices, as reported by an HR manager or executive. Fulmer et al. found that firm differences on their employee relations/attitudes measure were stable over time (i.e., an enduring resource or capability), rare (most firms do not have such high levels of mean employee attitude), and added value, as indicated by subsequent financial performance being higher for companies having the most favorable employee relations. Thus, employee relations seems to meet the RBV tests for a resource that can help generate sustained competitive advantage.

The Fulmer et al. (2003) approach is consistent with other approaches that emphasize aspects of employee relations that are "softer" than standard HR practice measures. Examples of these alternative approaches include ideas such as intangible assets and organization culture. According to Barney (1986, 664), "precisely because an organization's culture is hard to describe... and because even if the culture can be described, it is difficult to change; a firm's culture can hold promise for sustained superior financial performance for some firms." As another example, consistent with Fulmer et al. (2003), Gittell, von Nordenflycht, and Kochan (2004) focus on the importance of the "employment relationship," which they define as the "quality of relationships with employees" and they argue that this is more important than structural factors such as shared governance and wages."3 In summary, alternative ways of defining HR (e.g., in terms of employee relations, culture) may fit the RBV especially well. Yet, this alternative approach has received relatively little attention in the HR research literature.

A proponent of the standard HR practices and performance paradigm would likely observe that an exclusive focus on employee relations, culture, and related concepts leaves unanswered the question of how firms influence these concepts. In our view, this is an important question and one that needs to be addressed in the near future. However, we feel it is quite important to be open to the possibility that HR practices, as measured in the typical paradigm, will not necessarily show a strong relationship with employee relations or related measures such as culture.

3 Tsui et al. (1997) also use the concept of the employment relationship. Although their design relied on managerial responses to HR practice items, they did use multiple raters (to describe the employment relationship at the job level of analysis). 
In our view, the employee relations/attitudes measure is fundamental, given both the logic behind the importance of employee relations and its empirical relationship with performance at all levels of analysis, whatever its relationship with existing HR practice measures. Any lack of a significant relationship between HR practice and employee relations measures would suggest to us the need to re-conceptualize the HR practices and performance paradigm. (This might, of course, include reconfiguring its measures.)

Our suggestion is that the paradigm on HR practices and performance consider the following possibilities. First, and most important, firms may be able to achieve superior employee relations and superior performance via different paths. In other words, different combinations or configurations of HR practices can help different firms achieve the same outcomes. This is essentially the concept of equifinality, which Delery and Doty (1996) have previously applied to the HR-performance literature. However, little if any work has followed their lead. We note that the concept of equifinality may help explain the inconsistency across studies in defining just what exactly are desirable HR practices (Becker/Gerhart 1996; Boxall/Purcell 2003). This inconsisistency is to be expected if different firms use different configurations of HR practices to achieve AMO outcomes, strong employee relations and firm performance. ${ }^{4}$

Second, it is also possible that some of the HR practices that have received significant attention in the literature will prove to be only weakly related to employee relations, as suggested above. The employee survey used to select companies for the 100 Best list, as described earlier, focuses on areas such as credibility, respect, fairness, pride, and camaraderie. However, in the HR practices literature, the closest thing to a conceptual framework is the emphasis on practices that are expected to influence the workforce's ability, motivation, and opportunity to contribute. Motivation is probably most closely related to employee relations, but the typical (though not to say exclusive) focus of HR practice items in this area seems to be on pay for performance and promotion policies. Although effectively implemented practices in these areas can have substantial effects on performance (Gerhart/Rynes 2003), in many cases, implementation is not successful. In addition, pay, while important, is not the sole factor in motivation, and it is certainly not the sole factor in employee relations.

Thus, credibility, respect, fairness, pride, and camaraderie, key employee relations factors among the 100 Best Companies to Work For, may be largely untapped by most studies of HR practices. For example, supervisors that show respect to employees and value their contributions on a day to day basis, as well as informal social norms of interaction and more formal social activities that build social ties and cele-

4 Our discussion might imply that firms can compete only through using a "high road" HR strategy that is defined either in terms of using best HR practices or in terms of having strong employee relations and attitudes. There are, of course, firms that compete using "low road" strategies characterized by low wages and low investment in employee relations. The question with this strategy is whether it provides sustained competitive advantage or whether the advantage is fleeting. Short-term advantage may be all that some firms and investors wish to achieve. We have chosen to focus our discussion, however, on HR strategies that have the potential to provide longer lasting advantage. 
brate success, may be especially important determinants of employee relations. These then would somehow need to be better incorporated in studies of HR practices. Else, the standard HR practices and performance paradigm may miss too much that is important in HR.

A third possibility to consider is that HR practices, as typically measured, do not necessarily relate significantly to AMO outcomes, even though these are the very outcomes that seem to have originally guided the construction of HR practice items. For example, many studies include practices having to do with hours of training provided, which should relate to ability, yet many of these same studies ignore employee selection practices, which will also influence ability (Gerhart, forthcoming). I am unaware of research that explicitly links HR practices and AMO outcomes in the HR practices and business performance literature.

A fourth issue is that the formal or stated HR practice may look very different from how the practice is actually implemented. For example, in many studies, opportunity to contribute is measured in terms of the percentage of employees in various sorts of teams. However, such studies do not ask employees whether such formal mechanisms actually translate into them having significant opportunity to contribute by taking on a broader set of responsibilities, being granted more decision autonomy, and so forth. One study that did look at the correspondence between stated practice and employee perceptions in this area found correspondence to quite limited Gerhart (2002).

\section{Conclusion}

Research on the relationship between HR and business performance has proven to be of great interest to academics, as evidenced, for example, by the many awards won by such research. In addition, work in this area has the potential to provide important implications for practice. In this paper, however, I argue that certain questions need to be answered to provide greater confidence in the validity of findings and the resulting implications for practice. The now standard paradigm in the strategic HR literature defines HR almost exclusively in terms of HR practices (as reported by a single managerial respondent). I have suggested an alternative approach that focuses on studying employee relations as measured using an employee survey. Attention to related concepts such as culture might also prove useful. I have also offered suggestions on how this approach might be integrated with the standard paradigm. A key point, however, is that this integration may require changes in the standard paradigm's approach to the measurement of HR, as well as an expansion of its conceptual focus.

\section{References}

Appelbaum, E./Bailey, T./Berg, P./Kalleberg, A. (2000): Manufacturing Advantage: Why high performance work systems pay off. Ithaca, NY: Cornell University Press.

Arthur, J. B. (1994): Effects of human resource systems on manufacturing performance and turnover. In: Academy of Management Journal, 37: 670-687.

Bailey, T. (1993): Discretionary Effort and the Organization of Work: Employee Participation and Work Reform Since Hawthorne. Unpublished manuscript, Teachers College, Columbia University, New York.

Barney, J. B. (1986): Organizational culture: Can it be a source of sustained competitive advantage. In: Academy of Management Review, 11: 656-665. 
Barney, J. B. (1991): Firm resources and sustained competitive advantage. In: Journal of Management, 17: 99-120.

Barney, J. B./Wright, P. M. (1998): On becoming a strategic partner: The role of human resources in gaining competitive advantage. In: Human Resource Management, 37(1): 31-46.

Batt, R. (2002): Managing customer services: Human resource practices, quit rates, and sales growth. In: Academy of Management Journal, 45: 587-597.

Becker, B./Gerhart, B. (1996): The Impact of Human Resource Management on Organizational Performance: Progress and Prospects. In: Academy of Management Journal, 39: 779-801.

Becker, B./Huselid, M. A. (1998): High performance work systems and firm performance: A synthesis of research and managerial implications. In: Ferris G. F. (ed.): Research in Personnel and Human Resources, 16: 53-101, Greenwich, CT: JAI Press, Inc.

Boxall, P./Purcell, J. (2003): Strategy and human resource management. Hampshire, England: PalgraveMacmillan.

Bowen, D. E./Ostroff, C. (2004): Understanding HRM-firm performance linkages: The role of the 'strength' of the HRM system. In: Academy of Management Review, 29: 203-221.

Cappelli, P./Neumark, D. (2001): Do 'High-Performance' Work Practices Improve Establishment-Level Outcomes? In: Industrial and Labor Relations Review, 54(4): 737-775.

Cutcher-Gershenfeld, J. (1991): The impact on economic performance of a transformation in workplace relations. In: Industrial and Labor Relations Review, 44: 241-260.

Delery, J. E./Doty, D. H. (1996): Modes of Theorizing in Strategic Human Resource Management: Tests of Universalistic, Contingency, and Configurational Performance Predictions. In: Academy of Management Journal, 39: 802-835.

DeShon, R. P. (1998): A cautionary note on measurement error corrections in structural equation models. In: Psychological Methods, 3: 412-423.

Dyer, L./Reeves, T. (1994): HR strategies and firm performance: What do we know and where do we go from here? Working paper, 94-29, Center for Advanced Human Resource Studies, Cornell University.

Fulmer, I. S./Gerhart, B./Scott, K. S. (2003): Are the 100 best better? An empirical investigation of the relationship between being a 'great place to work' and firm performance. In: Personnel Psychology, 56: 965-993.

Gerhart, B. (forthcoming): HR systems. In: C. Ostroff/T. Judge (eds. ): Perspectives on Organizational Fit. San Francisco: Jossey-Bass (SIOP Frontiers Series).

Gerhart, B. (2002): Employee attitudes and high performance work practices: Does one have much to do with the other? University of Bath Conference on Strategic HR, April.

Gerhart, B. (1999): Human resource management and firm performance: Measurement issues and their effect on causal and policy inferences. In: P. Wright/L. Dyer/J. Boudreau/G. Milkovich (eds. ): Strategic human resources management in the twenty-first century. Supplement to G. R. Ferris (ed.): Research in personnel and human resources management. Stanford, CT: JAI Press.

Gerhart, B./Milkovich, G. T. (1990): Organizational differences in managerial compensation and financial performance. In: Academy of Management Journal, 33: 663-691.

Gerhart, B./Rynes, S. L. (2003): Compensation: Theory, evidence, and strategic implications. Thousand Oaks, CA: Sage.

Gerhart, B./Trevor, C./Graham, M. (1996): New Directions in Employee Compensation Research. In: G. R. Ferris (ed.): Research in Personnel and Human Resources Management: 143-203.

Gerhart, B./Wright, P. M./McMahan, G. C. (2000): Measurement error in research on the human resources and firm performance relationship: Further evidence and analysis. In: Personnel Psychology, 53: 855-872.

Gerhart, B./Wright, P. M./McMahan, G. C/Snell, S. A. (2000): Measurement error in research on human resources and firm performance: How much error is there and how does it influence effect size estimates? In: Personnel Psychology 53: 803-834.

Gittell, J. H./von Nordenflycht, A./Kochan, T. A. (2004): Mutual gains or zero sum? Labor relations and firm performance in the airline industry. In: Industrial and Labor Relations Review, 57: 163-179.

Godard, J. (2004): A critical assessment of the high-performance paradigm. In: British Journal of Industrial Relations, 42: 349-378. 
Godard, J./Delaney, J. T. (2000): Reflections on the 'high-performance' paradigm's implications for industrial relations as a field. In: Industrial and Labor Relations Review 53: 482-502.

Guest, D./Michie, J./Sheehan, M./Conway, N. (2003): A UK Study of the Relationship between Human Resource Management and Corporate Performance. In: British Journal of Industrial Relations, 41: 291-314.

Harter, J. K./Schmidt, F. L./Hayes, T. L. (2002): Business-unit-level relationship between employee satisfaction, employee engagement, and business outcomes: A meta-analysis. In: Journal of Applied Psychology, 87: 268-279.

Huselid, M. A. (1995): The impact of human resource management practices on turnover, productivity, and corporate financial performance. In: Academy of Management Journal, 38: 635-672.

Huselid, M. A./Becker, B. E. (2000): "Comment on 'Measurement Error in Research on Human Resources and Firm Performance: How Much Error is There and How Does it Influence Effect Size Estimates?' by Gerhart, Wright, McMahan, and Snell. Personnel Psychology 53: 835-854.

Ichniowski, C./Kochan, T. A./Levine, D./Olson, C. A./Strauss, G. (1996): What works at work: Overview and assessment. In: Industrial Relations, 35: 299-333.

Ichniowski, C./Shaw, K./Prennushi, G. (1997): The effects of human resource management practices on productivity: A study of steel finishing lines. In: American Economic Review, 87: 291-313.

Judge, T. A./Thoresen, C. J./Bono, J. E./Patton, G. K. (2001): The job satisfaction-job performance relationship: A qualitative and quantitative review. In: Psychological Bulletin, 127: 376-407.

Katz, H. C./Kochan, T. A./Gobeille, K. R. (1983): Industrial relations performance, economic performance, and QWL programs: An interplant analysis. In: Industrial and Labor Relations Review, 37, 3-17.

Katz, H. C./Kochan, T. A./Weber, M. R. (1985): Assessing the effects of industrial relations systems and efforts to improve the quality of working life on organizational effectiveness. In: Academy of Management Journal, 28: 509-526.

Lado, A. A./Wilson, M. C. (1994): Human resource systems and sustained competitive advantage: A competency-based perspective. In: Academy of Management Review, 19: 699-728.

Levering, R./Moskowitz, M. (1998): The 100 best companies to work for in America. In: Fortune, January 12: 84-95.

Macduffie, J. P. (1995): Human Resource Bundles and Manufacturing Performance: Organizational Logic and Flexible Production Systems in the World Auto Industry. In: Industrial and Labor Relations Review, 48: 197-221

Osterman, P. (2000): Work reorganization in an era of restructuring: Trends in diffusion and effects on employee welfare. In: Industrial and Labor Relations Review 53: 179-196.

Ostroff C. (1992): The relationship between satisfaction, attitudes, and performance: An organizational level analysis. In: Journal of Applied Psychology, 77: 963-974.

Pfeffer, J. (1994): Competitive advantage through people. Boston: Harvard Business School Press.

Ryan, A. M./Schmit, M. J./Johnson, R. (1996): Attitudes and effectiveness: Examining relations at an organizational level. In: Personnel Psychology, 49: 853-882.

Schmidt, F. L./Hunter, J. E. (1996): Measurement error in psychological research: Lessons from 26 research scenarios. In: Psychological Methods, 1: 199-223.

Schneider, B./Hanges, P. J./Smith, B./Salvaggio, A. N. (2003): Which comes first: employee attitudes or organizational financial and market performance. In: Journal of Applied Psychology, 88: 836-851.

Terpstra, D. E./Rozell, E. J. (1993): The relationship of staffing practices to organizational level measures of performance. In: Personnel Psychology, 46: 27-48.

Tsui, A./Pearce, J. L./Porter, L./Tripoli, A. M. (1997): Alternative Approaches to the EmployeeOrganization Relationship: Does Investment in Employees Pay Off? In: Academy of Management Journal, 40: 1089-1121.

Wright, P. M./Sherman, W. S. (1999): Failing to find fit in strategic human resource management: Theoretical and empirical problems. In: P. Wright/L. Dyer/J. Boudreau/G. Milkovich (eds. ): Strategic human resources management in the twenty-first century. Supplement to G. R. Ferris (ed.): Research in personnel and human resources management. Stanford, CT: JAI Press.

Wright, P. M./Gardner, T. M./Moynihan, L. M./Park, H. J./Gerhart, B./Delery, J. E. (2001): Measurement error in research on human resources and firm performance: Additional data and suggestions for future research. In: Personnel Psychology, 54: 875-901 